\title{
One dogma of philosophy of action
}

\author{
Matthew Noah Smith ${ }^{1}$
}

Published online: 16 December 2015

(C) The Author(s) 2015. This article is published with open access at Springerlink.com

\begin{abstract}
An oft-rehearsed objection to the claim that an intention can give one reasons is that if an intention could give us reasons that would allow an agent to bootstrap herself into having a reason where she previously lacked one. Such bootstrapping is utterly implausible. So, intentions to $\varphi$ cannot be reasons to $\varphi$. Call this the bootstrapping objection against intentions being reasons. This essay considers four separate interpretations of this argument and finds they all fail to establish that non-akratic, nonevil, and deliberatively sound intentions cannot be reasons. The first argument is the argument from evil intentions, the second is the argument from akratic intentions, the third is the argument from errors in deliberation, and the last is what I call the 'wizardry' argument. This 'argument', put forward most clearly by John Broome, claims that intentions are so insubstantial that were they on their own reasons for action, that would amount to creating something out of nothing and that is impossible. The essay argues that the claim that intentions are insubstantial is too strong a premise to put forward without argument. For there are other attitudes that are on their own sufficient to generate reasons, such as loving attitudes. The essay then argues that the bootstrapping objection's status as dogma in the philosophy of action has led to insufficient attention being paid to the entirely reasonable question of whether intentions are sufficiently like other reasongiving attitudes, such as loving and valuing. It may turn out that, just as loving someone can give the loving person a reason to act in a certain, so too can intending to do something give someone a reason to act in a certain way, but we cannot effectively engage this question without first giving up our commitment to the bootstrapping objection as a central "insight" in philosophy of action. The essay concludes by proposing two research questions that are opened up by the
\end{abstract}

Matthew Noah Smith

m.smith@leeds.ac.uk

1 School of PRHS, University of Leeds, G.10 Michael Sadler Building, Woodhouse Lane, Leeds, West Yorkshire LS2 9JT, UK 
abandonment of the bootstrapping objection as dogma, and proposes that we turn our philosophical attentions to those questions.

Keywords Philosophy of action - Bootstrapping · Intentions · Reasons · Normativity · Rationality

\section{Introduction}

Philosophers often object to the claim that an intention can give one reasons by arguing as follows. If an intention could give us reasons, then that would allow an agent to bootstrap herself into having a reason where she previously lacked one. But, such bootstrapping is utterly implausible. So, intentions to $\varphi$ cannot be reasons to $\varphi .{ }^{1}$ This is the bootstrapping objection against intentions being reasons. ${ }^{2}$

Some philosophers have resisted the application of the bootstrapping objection. For example, although he presented what became one of the canonical formulations of the bootstrapping objection, Michael Bratman recently attacked the bootstrapping objection by arguing that an existing intention to $\varphi$ can sometimes give one a reason to take the means to $\varphi$-ing, where these are non-instrumental reasons of selfgovernance. ${ }^{3}$ Bratman's argument begins with a defense of the claim that conforming to a norm of means-end coherence in intentions is constitutive of self-governance. But, since (he assumes) we have reasons to be self-governing, then we have non-instrumental reasons to conform to a norm of means-end coherence. ${ }^{4}$

Much of the resistance to views like Bratman's (as well as to constructivist views that appear to involve some kind of bootstrapping $)^{5}$ is due to a deeply held commitment to the bootstrapping objection. This commitment is widespread, ironically due to Bratman's own early efforts. In fact, the bootstrapping objection is probably the closest thing there is to dogma in the philosophy of action and the

\footnotetext{
${ }^{1}$ For the initial canonical statement, see Bratman (1987). Other statements include: Richard Holton writes that "Forming an intention to do something surely cannot give one a reason to do it that one would not otherwise have. If it did, we could give ourselves a reason to do something just by intending to do it; and that cannot be right." (Holton 2004). John Broome writes that "it is not credible that, just by adopting some end, you make it the case that you have reason to pursue it" (2005b, Symposium 1). Joseph Raz denies the "blanket conclusion that having goals or intentions provides reasons" (2005, Symposium 1). For other statements of the bootstrapping objection as applied to both reasons for action and means-end coherence, see Broome (2001, 2004, 2005a), Setiya (2007) (Setiya describes bootstrapping as "illicit" but then goes on to defend a belief-based 'cognitivist' version of bootstrapping from the bootstrapping objection); and Cullity (2008, pp. 57-95). See also the discussion in Ferrero (2010, especially pp. 3-6). A very important and influential related discussion appears in Korsgaard (1997). There are many more examples.

${ }^{2}$ This version of the bootstrapping objection concerns only reasons for action and should be distinguished from epistemic bootstrapping. For more on epistemic bootstrapping, see, e.g., Cohen (2002, 2010), Vogel (2008), and quite generally Weisberg (2012).

${ }^{3}$ Bratman (2009).

${ }^{4}$ This is a very rough sketch of Bratman's complicated and compelling view.

${ }^{5}$ See, e.g., Gibbard's objections in his (1990: 140-164, 145). For a response to Gibbard, see Street (2009).
} 
philosophy of normativity. Given its status as dogma, there hasn't been much exploration of the foundations of the bootstrapping objection. ${ }^{6}$ Instead, the usual practice is either to recite, catechism-like, the claim that intending to do something cannot give one reasons because that would be illicit bootstrapping, or to cite a few cases that supposedly conclusively demonstrate that bootstrapping is impossible in all relevant cases. The former approach - the mere recitation of the antibootstrapping creed-fails to provide philosophical illumination. The latter approach-citing cases-presents itself as a philosophically robust case against bootstrapping. But, citing cases provides us only with epistemic reasons (although perhaps strong epistemic reasons) to believe that the bootstrapping objection is sound. Citing cases does not immediately reveal any explanation for why the bootstrapping objection is sound.

So, we need to look further to find the deeper philosophical commitments supporting the bootstrapping objection. This essay takes up that task, albeit skeptically. Its aim is to show that the bootstrapping objection is not as philosophically robust as typically assumed to be. I argue for suspension of judgment about the applicability of the bootstrapping objection to certain kinds of intentions. The essay therefore doesn't argue that intentions are reasons. Pursuit of that goal is left for another time.

\section{Overview}

The bootstrapping objection is typically presented as applying to all intentions. It is not hedged to cover only odd cases, such as only akratic intentions or only evil intentions or only intentions formed as a result of poor deliberation. ${ }^{7}$

One reason for this is that a central question in philosophy of action is how to understand the normative significance of our practical attitudes. ${ }^{8}$ The bootstrapping objection can block one route towards resolving these puzzles, namely, the route that goes via the reason-giving force of intentions. In this way, the bootstrapping objection opens the way for some general claims about practical reasons and rationality like, e.g., that we must reinterpret intentions as beliefs of some sort or that we must reinterpret the normative significance of intentions in terms of a 'lesser' kind normativity like Broomean normative requirements.

To defeat the bootstrapping objection, then, I merely need to show that it doesn't apply to at least one important class of intentions. That does not mean that I must demonstrate that at least some intentions are reasons. Rather, I need only to show

\footnotetext{
6 The exception is Pillar (2013). Pillar's discussion bears some similarity to the following, although it focuses exclusively on Broome's views.

7 When John Broome, for example, writes, “...it is not credible that, just by adopting some end, you make it the case that you have reason to pursue it," he is giving his view, not offering a summary in which he leaves out hedges (Broome, "Have We Reason to Do as Rationality Requires? A Comment on Raz," p. 1). See also the references in footnote 1 above, none of which hedge. But, see Bratman's querying of the bold formulation of the bootstrapping objection in footnote 19 of "Intentions, Practical Rationality and Self-Governance," pp. 416-417.

${ }^{8}$ I thank Kieran Setiya for discussion on this point.
} 
that the bootstrapping objection as it is typically presented applies only to a small class of deviant intentions and that in the absence of further argument we cannot generalize from those deviant cases to all intentions.

More specifically, anti-bootstrappers assume that the intentions to which they appeal in their arguments are paradigmatic intentions. They do this because if the intentions they claim are subject to the bootstrapping objection are paradigmatic intentions, then valid and informative generalizations can be made on the basis of the characteristics of those intentions. I argue that the intentions on which the bootstrapping objection focuses are in fact ugly and broken intentions, formed as a result of evil reasoning or bad reasoning. Such defective intentions are at best paradigms of what evil or bad reasoning yields. Why, one may reasonably ask, should we treat outputs of malfunctioning processes as paradigms for the sake of making generalizations about the outputs of well-functioning processes? We should, instead, focus our study on the well-functioning processes and their outputs.

Before turning to the main arguments, it is worth noting that the bootstrapping objection does not typically target an especially strong or peremptory intentiongrounded reason. The bootstrapping objection is concerned with all intentiongrounded reasons, be they conclusive reasons, sufficient reasons, peremptory reasons, or just one reason among many. If, after reading this essay, a defender of the bootstrapping objection decides to restrict her focus to a special class of intention-grounded reasons such as peremptory reasons, then this essay will still have made some contribution to the literature. For, were philosophers to begin explicitly treating the bootstrapping objection as targeting only intention-grounded peremptory or conclusive reasons, that would be a significant departure from the way in which the bootstrapping objection is typically presented. ${ }^{9}$

In the remainder of the essay, I consider in turn four ways people might argue for the bootstrapping objection: the argument from evil intentions, the argument from akratic intentions, the argument from errors in reasoning, and what I shall call the 'wizardry argument.'

\section{The argument from evil intentions}

Some try to show that the bootstrapping objection is devastatingly forceful by arguing as follows. ${ }^{10}$ Suppose bootstrapping were possible. Suppose someone intends to act wrongly. One thereby has a reason to act wrongly. But it is obviously implausible that one can have a reason to act wrongly. Therefore, bootstrapping is impossible: no intention could be a reason.

\footnotetext{
9 Mark Schroeder develops and exploits this point at length in an essay that has similar aims as this essay (2005a, Symposium 1). See especially pp. 8ff.

${ }^{10}$ For example, see Raz, "Instrumental Rationality: A Reprise," and Raz, "The Myth of Instrumental Rationality." See also Bratman, "Intention, Practical Rationality, and Self-Governance," and citations therein. Bratman ends with worries about Iago, whose intentions to act wrongly may give him a reason to act wrongly.
} 
This argument is unsound. First, the inference from the claim that some intentions, namely, intentions to act wrongly, are not reasons to the claim that all intentions, whatever their content and deliberative history, are not reasons is unwarranted. Second, one of the premises of the argument is false. For, there are instances in which one has reasons to act wrongly. I shall primarily focus on this second point.

A central question philosophers have asked about morality is how to manage the tensions between prudential reasons, which can be reasons to act wrongly, and moral reasons, which are reasons to act as morality requires. If it were obvious that we never had prudential reasons to act immorally, then these tensions would never arise and there would be no meaningful philosophical questions here. But, the tensions between prudence and morality are (alas) all too easy to appreciate, and there are plenty of meaningful philosophical questions regarding this topic.

Suppose someone is shooting at other people. One could stop the shooter by rushing him, although one will probably die in the process. Suppose one is obligated to risk one's life in this way. One still has a strong reason of self-preservation to run away from the shooter. But that is a reason to act in a way that is contrary to how one is obligated to act, so one has a reason to act wrongly. This becomes quite clear once we reflect on the fact that we so highly praise the person who risks their life largely because that person has such a strong reason to run away. Some morally required actions come at great personal cost and that cost can be characterized in part in terms of the reasons one had not to incur that personal cost.

Cases of reasonable moral mistakes also supply us with examples of reasons to act wrongly. Suppose one reasonably believes that one (morally) ought to $\varphi$ but in fact one (morally) ought to $\psi$. It also happens that $\psi$-ing is incompatible with $\varphi$-ing. One explanation for such a reasonable mistake is that there are in fact many reasons to $\varphi$ in addition to the many reasons to $\psi$. Such cases-cases in which it is difficult to determine what the 'balance of reasons' is - may not be unusual. That there are many, many reasons to do the wrong thing would explain why good and intelligent people throughout history were so often wrong about what morality required of them.

It seems, then, that reasons to act wrongly are fairly common. So, the argument from evil intentions is unsound because it (at least) contains a false premise.

\section{The argument from really evil intentions}

Anti-bootstrappers may be tempted to double down on the argument from evil intentions, arguing that the response above somehow misses the point. Disgusted, they demand that the pro-bootstrapper consider an intention to commit genocide, where this intention to commit genocide is adopted because of perverse ideology (where argument fails, just invoke the Nazis, I guess). It is incredible, they say, that a person's ideologically driven intention to commit genocide can be a reason for that person to commit genocide. This shows that all bootstrapping is impossible.

Alas, it is unwarranted to infer from (1) the proposition that ideologically-driven evil intentions cannot be reasons to (2) the proposition that every intention cannot be 
a reason. What the anti-bootstrapper needs is an argument demonstrating that intentions produced by the morally defective and ideologically warped exercise of agency are relevantly indistinguishable from non-evil intentions produced by the morally acceptable exercise of agency (all intentions are Nazi-intentions!). In the absence of such argument, intellectual prudence recommends demurring from hasty universal inferences made on the basis of intuitions about Nazi decision-making.

There just aren't any existing versions of the argument from evil intentions that block the pro-bootstrapper from energetically joining in with her frustrated antibootstrapping colleague as he chants the anti-bootstrapping catechism: "An intention to commit genocide cannot be a reason to commit genocide!" At some point, the pro-bootstrapper should add, "But an intention to help the global poor through activism or effective altruism, so long as it is the product of sound deliberation, is itself a reason to do just those things!" What cunning response does the anti-bootstrapper committed to the argument from evil intentions have to this clunky new addition to his creed ${ }^{11}$

\section{The argument from akratic intentions I}

Let us turn now to the argument from akratic intentions. We owe the canonical formulation of this argument to Bratman. ${ }^{12}$ As initially presented in Intentions, Plans, and Practical Reasons, it is quite detailed, but recently Bratman neatly summarized the essence of this formulation of the bootstrapping objection (all in the service of ultimately arguing for a kind of bootstrapping):

Suppose, that my decision in favor of end E is irrationally akratic: my stable best judgment about the balance of reasons favors an alternative end $F$ over E. If my intention in favor of $\mathrm{E}$ were in general to provide a further reason for the means to $E$, then such a reason would favor the means to $E$ even when my intention in favor of $\mathrm{E}$ is akratic. Such a reason might then tilt the balance of reasons in favor of the means to E over the means to F. This would be an odd kind of bootstrapping of the case in favor of the means to E over the case in favor of the means to F. After all, from my own point of view the intention in favor of $\mathrm{E}$ is ill-advised. Why would I, in general, suppose that

\footnotetext{
11 Imagine if the anti-bootstrapping catechism were, suitably altered, leveled against utilitarianism: "A pleasure associated with genocide cannot be a valuable feature of genocide!" We are all familiar with this sort of anti-Benthamite sloganeering, and few believe it alone refutes utilitarianism. Why should we take it seriously as a conclusive demonstration of bootstrapping's impossibility when similar rally cries blow forth from the mouths of anti-bootstrappers?

12 Bratman, Intentions, Plans, Practical Reasons, pp. 24-27, and then picked up by almost every author writing on the topic since. For a recent example, see Setiya (2014, pp. 56-82, 57-59). As noted above, although Bratman's description of bootstrapping is canonical, Bratman himself does not endorse a general anti-bootstrapping position.
} 
this intention nevertheless provides me yet one more reason in favor of the means to $\mathrm{E}$ over the means to $\mathrm{F}$ ? $^{13}$

Bratman's formulation, though, is not as powerful as it at first seems. For, it depends for its force on the akratic character of the agent's intention. But akrasia is a feature of deeply compromised agency. Given this fact, we may reasonably ask the following: Are akratic intentions sufficiently like non-akratic intentions such that non-akratic intentions, aside from being non-akratic, share all the same features possessed by akratic intentions? It seems unlikely that this is so.

As an analogy, consider the noises made by broken tubas. These are not the same as the noises made by well-functioning tubas. Why infer that all tubas are sources of unpleasant noises on the basis of hearing the repellant honks produced by the tuba that fell down the stairs? Similarly, akratic agency is like the busted tuba: it is defective. And, like a broken tuba's loud, unnerving toots, akratic intentions, which are key products of akratic agency, are also defective. In both cases, we are considering the unwholesome expressions of malfunctioning things.

Nothing licenses making, on the basis of observations of what the corrupt and broken produce, universal claims about what expertly operated, well-functioning things can produce. The only obvious claim one can make upon close inspection of broken things produced by broken processes is this: When one properly uses a well functioning system, the outputs are going to be in many ways better than the broken outputs of broken versions of those systems.

In the absence of further argument, there is no reason to suppose that akratic intentions are in the relevant ways indistinguishable from the intentions produced by properly functioning agency. All we can conclude from Bratman's appeal to akratic intentions is that they cannot be sources of reasons. So much the worse for akratic agency! We've learned little about whether well-functioning agency has reasongenerating powers.

So, one could — and perhaps should — both accept that the bootstrapping objection applies to cases of akratic intentions and reserve judgment on the question of whether acceptance of this claim commits one to the claim that intentions produced by healthy deliberations by healthy agents are not reasons. Such forbearance is especially apt given the aim of philosophy of action. Philosophy of action begins with the exploration of non-defective, healthy agency and, in particular, with intentions and actions produced by non-defective, healthy agency (just as music theory focuses on music competently produced by the use of properly functioning instruments). Akrasia and akratic intentions are important topics of inquiry. But akratic agency is not agency's paradigmatic form and akratic intentions are not the paradigmatic form of intention.

In short, the appropriate conclusion to draw from Bratman's example is that the failure of akratic intentions to generate reasons is probably best explained by those

\footnotetext{
13 Bratman, "Intention, Practical Rationality, and Self-Governance," pp. 415-416. Bratman explicitly notes that he is recapitulating his argument from Intentions, Plans, and Practical Reason. At footnote 16 on p. 416, which accompanies the text quoted in the main body of the present essay, Bratman writes, "This kind of example was a main concern of mine in Intention, Plans, and Practical Reason, 24-27."
} 
intentions being akratic. It is not best explained by the fact that those akratic intentions are intentions. ${ }^{14}$ For, the best explanation for the normative insignificance of defective intentions is the very thing that made those intentions defective, namely, their being akratic. It is actually sort of bizarre to think that the best explanation for defective intentions not being reasons is that those defective intentions are intentions.

So, the argument from akratic intentions does no more than suggest the further question, "But, can non-akratic intentions be reasons?" It does not supply us with an answer to that question.

\section{The argument from akratic intentions II}

Another canonical version of the bootstrapping objection targets the non-akratic agent. This version of the bootstrapping objection focuses on agents who make errors in deliberation. John Broome is a well-known proponent:

Suppose you are wondering whether to visit Paris, but have not yet made up your mind. There are reasons in favour and reasons against. Whether or not you ought to go depends on the balance of reasons. Now suppose you make up your mind to go, so now you intend to go to Paris... Suppose there is a slight balance of antecedent reasons against going, but you made a mistake in your calculations and wrongly decided to go. A short time later, having invested nothing in the decision, you discover your mistake. Should you change your mind? If intentions were reasons, there would automatically be a reason not to, and if the balance of antecedent reasons was slight enough, you should stick to your decision. But actually you should surely change your mind. Since you have invested nothing in your wrong decision, you should change it. ${ }^{15}$

Call this the argument from errors in reasoning.

Let us interpret Broome as considering cases in which one realizes either that one has deliberated on the basis of a false belief or that one has failed to appreciate that certain interests are not as significant as they at first appeared. In such cases, Broome seems to be saying, if bootstrapping were possible, then one could somehow reverse one's error in reasoning by doubling down on that error. One does this by knowingly committing to the intention produced by the error-filled reasoning. This reversal of error by knowingly committing to the error, which seems to amount to making a second error, is implausible. So, bootstrapping must be impossible.

In response, pro-bootstrappers can both endorse bootstrapping and argue that even if intending to $\varphi$ on the basis of bad deliberations gives one a new reason to $\varphi$, realizing that one has deliberated incorrectly gives one yet another new and even

\footnotetext{
14 Analogously, the failure of the defective heart to pump blood correctly is probably best explained by the heart's being defective not by the heart's being a heart.

15 Broome, “Are Intentions Reasons?” p 99.
} 
stronger reason in favor of abandoning that intention. ${ }^{16}$ So, one ought to give up the bootstrapped reason. In this way, the pro-bootstrapper can both agree with Broome when he writes that you should change your mind once you realize you've made a mistake in your reasoning and consistently defend bootstrapping.

Let's look at this a bit more carefully.

A pro-bootstrapper is not committed to the claim that once one intends to $\varphi$, one has settled the question for all eternity, come what may, about whether to $\varphi$. Bootstrapping occurs, if it occurs at all, because by deliberating about whether to $\varphi$ and then forming the intention to $\varphi$, one has changed the world. This change in the world, like all changes in the world, can be a source or a trigger of 'new' reasons. But, the pro-bootstrapper needn't hold that this is the end of the story. For, as Broome himself observes, once one deliberates badly and thereby forms a stupid intention, other things can also happen. In addition to the formation of the intention, one also (according to Broome's case) eventually gains the new knowledge that one has made a mistake in one's deliberations. That new knowledge can be a source of, or a trigger for 'new' reasons. So, if an intention to $\varphi$ is a reason to $\varphi$, then that reason still has to face up to whatever reasons are produced or triggered by the knowledge that one has deliberated very poorly in the lead-up to forming the intention. So, just as the pro-bootstrapper can argue that an intention to $\varphi$ can be a reason to $\varphi$, the pro-bootstrapper can also argue that the knowledge that one has made a mistake in one's deliberations about whether to $\varphi$ can also be a reason, and in this case a very powerful reason to abandon the intention to $\varphi$ and thereby to 'give up' the intention's concomitant reason.

So far, I've claimed that it is open to the pro-bootstrapper to argue that when one realizes one has made an error in one's deliberations, then one probably has overwhelming reason to reopen those deliberations. I think that this fact applies even in cases in which one doesn't realize that one has made an error in one's deliberations. Bad reasoning that leads to an intention is a practically significant phenomenon. Just like other practically significant phenomena, such as coming upon a person who needs your assistance, corrupt deliberations leading to an erroneous intention can create or trigger a reason. In particular, corrupt deliberations leading to an erroneous intention can create very strong reasons (1) to reopen those very deliberations and then (2) to try to re-deliberate correctly.

Since having an intention to $\varphi$ blocks further deliberation about whether to $\varphi$, it is also open to the pro-bootstrapper to argue that even if an intention to $\varphi$ is a reason to $\varphi$, corrupt deliberations, in virtue of being a reason to re-open the question about whether to $\varphi$, ultimately require giving up that intention to $\varphi$. Why? 'Reasons of bad deliberation' are reasons to re-open deliberations. But, in order to re-open deliberations one must abandon the intention in question. So, even if bootstrapping is possible, when one forms an intention on the basis of incorrect reasoning, one cannot, simply by forming that intention, permanently toggle the balance of reasons from favoring one course of action to favoring another course of action. For, while intending to $\varphi$ on the basis of corrupt deliberations may very well be a reason to $\varphi$

$\overline{16}$ A version of this view is explored in Richard Holton, "Rational Resolve." 
that on its own tips the balance of reasons in favor of $\varphi$-ing, that reason becomes irrelevant in the face of a much more powerful reason, namely, a reason, grounded in the bad deliberations, that requires one to re-open deliberations about whether to $\varphi$.

In short, when one makes an error in one's deliberations about whether to $\varphi$, and especially when one realizes one has made this error, the thing to do is not to $\varphi$ (or to do the opposite of $\varphi$-ing!). Rather, the thing to do is to stop and reconsider. One ought to try to eliminate the mistakes one made in one's deliberations in order to act on the best reasoning possible.

To illustrate this further, consider cases in which one luckily hits on the correct intention despite one's 'mistaken calculations.' Suppose I have many false beliefs. I also deliberate badly. But, like a broken clock that is correct twice each day, I sometimes luckily come to the correct conclusion about what I ought to do. Because I deliberated badly, I still ought to suspend that intention and re-open deliberations. That I accidentally hit upon the right answer about what to do is irrelevant. What matters is that my deliberations were corrupt. And this applies doubly if I know that I deliberated badly. So, in light of this, I ought not to $\varphi$ at that moment. What I ought to do at that moment is to reconsider whether to $\varphi$.

For example, suppose I drunkenly deliberate about whether to go to France, reasoning on the basis of (1) the false belief that if I go, I will meet and then become best friends with Serge Gainsbourg, (2) the ridiculous overweighting of my interest in becoming a famous French race car driver, and (3) the bad inference from the claim that I am best friends with Serge Gainsbourg to the claim that I will become a famous French race car driver. As a result of these false beliefs, stupid desires, and corrupt deliberations, I conclude that the balance of reasons favors my going to France. I thereby form the intention to go to France. Amazingly, the balance of reasons does favor my going to France because, unbeknownst to me, there are currently very cheap flights, I need a vacation, my best friends will all be there visiting exactly the places one might visit were one searching for Serge Gainsbourg, and the best vacation I could take now would be an inexpensive one to France to see all my best friends (who all happen to be Gainsbourg fans just like me). Should I hang on to my (objectively correct) intention to go France? No. At the moment I concluded my drunken deliberations, I ought not go to France. Why? Because were I to go to France at that moment, I would not merely be going to France, I'd be drunkenly going to France for the worst possible reasons! Those factors - that I am drunk, that I reasoned drunkenly, that my intention to go to France is based on laughably terrible considerations-are relevant to the question of whether I ought to go to France, just like considerations about the cheap flights, the presence of friends in France, etc. So, given my condition, what I ought to do is to abandon this drunkenly formed intention and to reconsider my deliberations soberly. When I reconsider, I will realize correctly that I ought to go to France. And so I will form the intention that, prior to my drunken reflections and decisions, the balance of reasons recommended.

So, even if intentions are reasons, only those reasons grounded in intentions that are products of sufficiently good deliberations can settle questions about how to live. Reasons grounded in intentions that are products of bad deliberations ought to be disregarded, regardless of whether these intention 'track' the balance of reasons. We ought instead to re-open deliberations and so we ought to abandon the poorly formed 
intentions. That is, even if intentions are reasons, those reasons are outweighed or defeated, or whatever, by the reasons grounded in one's erroneous deliberations.

It follows that when it comes to an intention produced by bad reasoning that the agent realizes is bad reasoning, it doesn't matter one way or another whether intentions are reasons. For, what one has strongest reason to do is abandon the intention in order to reconsider how to live. There is no sense in which a probootstrapper must be committed to the view that, through bad deliberations, one can fully settle the balance of reasons in favor of what, prior to the bad deliberations, one lacked overall reason to do.

\section{What can deliberations do?}

What should be clear is that the real debate ought to be centered on what counts as deliberations bad enough to require abandoning an intention and re-opening deliberations. ${ }^{17}$ This is a tough question. For example, it is unclear whether blamelessly having false beliefs one could have avoided are grounds for re-opening deliberations. It requires further investigation before any firm conclusions can be drawn. One might leach bootstrapping of its philosophical significance if one assumes without argument that all errors of deliberation, including all deliberations on the basis of any false beliefs, require abandoning one's intentions and re-opening deliberation. For, there are at least some considerations against re-opening deliberation even under conditions of uncertainty or error. ${ }^{18}$

For example, slightly wonky deliberations or a few false beliefs shouldn't require one to re-open deliberations. In these cases, the anti-bootstrapping intuition should not be very strong. Suppose, somewhat ridiculously (although this is how some of the literature suggests we should think about reasons), that $51 \%$ of the (weight of) reasons prior to deliberation support my not going to France and $49 \%$ of the (weight of) reasons support my going to France. I deliberate pretty well, but make a small error when considering just one of the reasons. Because of this error, I wrongly conclude that $50.1 \%$ of the (weight of) reasons support(s) my going to France. I straightaway form the intention to go to France. The world has now changed: on the basis of pretty good reasoning, I have settled for myself that I ought to go to France by forming the intention to go to France. Has my forming this intention tipped the balance of reasons in favor of my going to France? It seems that the strength of any argument from errors in reasoning comes down to dueling intuitions about these subtle close-call cases. All anti-bootstrappers who rest their view on the argument for errors in reasoning have offered us is the bare intuition that the balance of reasons has not shifted as result of my intention to go to France. A pro-bootstrapper may demur on letting that bare intuition settle the question and instead ask the philosophically substantive question: "Are intentions to $\varphi$ along

\footnotetext{
${ }_{17}$ For more on this, see Holton (1999). See also discussions in Bratman, Intentions, Plans, and Practical Reason, chapters 5 and 7.

18 See, e.g., Hinchman (2003), Richard Holton, "Rational Resolve," and Luca Ferrero, "Decisions, Diachronic Autonomy and the Division of Deliberative Labor."
} 
with their sources, namely, pretty good reasoning about whether to $\varphi$, sufficiently important to count as reasons to $\varphi$ ?" The bare intuition driving the argument from errors in reasoning does not cleanly, much less informatively, settle this question.

As further support for skepticism regarding the philosophical power of the bare intuition driving the argument from errors in reasoning, consider cases in which the balance of reasons is in perfect equipoise between $\varphi$-ing and not $\varphi$-ing. If bootstrapping is possible, then intending to $\varphi$ in this case upsets this balance in the direction of the content of the intention. The argument from errors in reasoning would have us believe that bootstrapping is obviously implausible in this case (since the intention would be formed on the basis of subtly incorrect deliberations which failed to pick up that the balance of reasons was in perfect equipoise). But, these sorts of cases might plausibly invite a pro-bootstrapping intuition. For, when we ask what the best tie-breaker would be for cases in which the balance of reasons is in perfect equipoise, it seems that an intention made on the basis of even slightly bad deliberations is an entirely reasonable sort of tie-breaker. Why, beyond a dogmatic need to deny that bootstrapping is possible would one, in the face of someone else's intuition that in these cases an intention can settle what the reasonable course of action would be, insist on the sovereignty of the intuition driving the argument from errors in reasoning? Does it seem equally obvious that flipping a coin or that just giving up on making any decision at all are the best responses to perfect equipoise? Is the anti-bootstrapper committed to the view that giving up control over one's life is more reasonable than or, at best, no less unreasonable than taking control of one's life through deliberating about how to live (even if these deliberations contain small errors)? My intuition, at least, is that this is a perverse view. I, at least, have the very strong intuition that the fact that someone has considered how to live and has decided that such-and-such a course of action is the one she will take is a perfectly good tie-breaker between two antecedently equally reasonable courses of action. In particular, by deciding that one course of action is the one to take, the agent breaks the tie and makes it the course of action she ought to take. It is not just a case of arational plumping. Why? Because well-founded intentions are reasons.

One might insist that I am begging the question here. My responses are as follows. First, we are firmly in the game of contrasting bare intuitions. If the antibootstrapper can rest a substantive normative thesis on the basis of the bare intuition behind the argument from errors in reasoning, then why cannot I do the same on the basis of another bare intuition? Second, and more substantively, any antibootstrapper who aims to demonstrate the anti-bootstrapping claim without begging the question must supply an explanation for why the pro-bootstrapping claim is false, where that explanation does not itself rest entirely on the bare antibootstrapping intuition. But my opponent merely repeats, catechism like, the claim that intentions grounded in errors in reasoning cannot be reasons. That provides no philosophically informative grounds for insisting that bootstrapping is always implausible. It amounts to no more than thumping the table and scoffing.

Notice further that the pro-bootstrapper in the imagined case is not arguing for a proposition that is as wild as the claims that pain is more valuable than pleasure or that saving one person is better than (or not morally distinguishable from) saving ten people. The pro-bootstrapper is saying that, if one intends to $\varphi$ on the basis of pretty 
good deliberations, and the reasons to $\varphi$ and the reasons not to $\varphi$ are in perfect equipoise with one another, then intending to $\varphi$ on the basis of pretty good deliberations can tip the balance of reasons in favor of $\varphi$-ing. In the absence of further argument against such a claim, only those who are already in the grips of the anti-bootstrapping dogma will find this view beyond the pale.

But we're not finished yet. Consider cases of underdetermination or indeterminacy. Suppose there are both many reasons to $\varphi$ and many reasons not to $\varphi$, but there is no determinate weighting of the reasons in these two sets such that 'the balance of reasons' supports one course of action over another. The 'support' for the bootstrapping objection comes from it being supposedly obviously implausible that an intention to $\varphi$ grounded in more or less sound reasoning could resolve this normative indeterminacy in favor of $\varphi$-ing. Once again, though, this is not an obviously implausible way to resolve the indeterminacy. Even more so than what it takes to resolve cases of the balance of reasons being in perfect equipoise, what it takes to resolve normative indeterminacy is a difficult question. The claim that intentions grounded in pretty good deliberations cannot on their own at least sometimes resolve such indeterminacy in favor of the intended action is a substantive philosophical claim. It cries out for justification that goes beyond bare intuition-mongering.

I conclude that the argument from errors in reasoning fails to show that nonakratic intentions that are products of acceptable deliberations cannot be reasons to $\varphi$.

\section{The wizardry argument}

There is one final interpretation of the bootstrapping objection that we can find if we look closely at Broome's discussion of bootstrapping. Before turning to this final version, it is worthwhile to note a prejudice some might have about reasons for action. This prejudice is that reasons for action pick out certain kinds of goodmaking features, broadly construed, of the actions they support. So, the bootstrapping objection might be understood as expressing the view that intending to $\varphi$ cannot be a good-making feature (broadly construed) of $\varphi$-ing. For, intending to $\varphi$ does not change $\varphi$-ing itself such that a new good-making feature of $\varphi$-ing comes into existence in virtue of intending to $\varphi$.

This prejudice is unwarranted. For, while one's attitudes towards an action do not change the intrinsic character of the action, one's attitudes towards an action can make it the case that one has a reason to take that action. That I want to take the stairs can be a reason to take the stairs. ${ }^{19}$ So, bearing a certain kind of psychological relationship to an action can be a reason to perform that action.

\footnotetext{
19 This is not a metaenormative claim about what grounds reasons. Rather, it is claim in first-order normative theory, namely the claim that desiring something, like that something being a good thing, can be a reason, albeit not a conclusive or sufficient reason, to pursue that thing.
} 
This is an instance of the general view that one has a reason to $\varphi$ when one is in the right kind of relation to $\varphi$-ing. ${ }^{20}$ Our task as philosophers is to identify principles that tell us which relations are such that being in those relations give us or don't give us reasons. For example, suppose A promises B that he, A, will $\varphi$. This promise gives A a conclusive reason to $\varphi$. Why? Because there is a general normative principle that says that being in a promising-relation to $\varphi$-ing generates for the promisor a conclusive reason to $\varphi .^{21}$ On the other hand, suppose $\mathrm{C}$ can financially afford to $\varphi$. This is not a reason for $\mathrm{C}$ to $\varphi$. For, there is no principle that says that being in the able-to-financially-afford-relation to $\varphi$-ing gives one a reason to $\varphi$.

With this in mind, let us consider the final interpretation of the bootstrapping objection, which Broome suggests in some of his writings. Broome's comments about bootstrapping suggest that he thinks that intending to $\varphi$ is more like being able to financially afford $\varphi$-ing than it is like promising to $\varphi$. On this account of the bootstrapping objection, then, the justification for skepticism about intention-based reasons depends upon the existence of a further normative principle that says that the intending-to- $\varphi$-relation is not significant. Intending to $\varphi$ just isn't sufficiently like, for example, promising to $\varphi$ such that it generates or triggers a reason to $\varphi$. For, while promising to $\varphi$ puts one into a substantive relationship with both another person and an act type, merely intending to $\varphi$ puts one in an insubstantial relationship to $\varphi$-ing. Such mental-relationships lack the 'reality' of a promising relationship. We cannot with just a flick of the mind conjure reasons from the vasty (psychological) deep; we can call them but they won't come. This is how we should understand John Broome when he writes that “...it is implausible that you can give yourself a reason, just by forming the intention of doing it. How can you create a reason for yourself out of nothing?" 22

I call this the 'wizardry argument' against bootstrapping. But is there any argument for the principle that says that being in an intending-relation to $\varphi$-ing is so insubstantial that it doesn't put one in a reasons-relation to $\varphi$-ing? In its absence, the anti-bootstrapper is forced simply to slap his head and complain that the probootstrapping arguments are no more than philosophical alchemy aiming to transform the lead of intentions into the gold of reasons. Let the rigorous science of reasons be your guide, the anti-bootstrapper insists. This science of reasons-and it is a science because according to it reasons have weights and all sorts of other seemingly mathematical features - has revealed to us that intending to $\varphi$ is just too close to nothing to be a reason to $\varphi$.

\footnotetext{
${ }^{20}$ I borrow (and tweak) this formulation from Schroeder (2005b). Nothing I say here is meant to engage Schroeder's argument in that essay. See also Enoch (2011).

${ }^{21}$ How does one defend this principle? Immanuel Kant defends a perfect duty not to make lying promises for the sake of gain in Grounding of the Metaphysics of Morals by appeal to the Formula of the Universal Law. David Hume gives a practice-based defense in (1742). Thomas Scanlon rejects this view in (1990) and (1998), chap. 7. But see Kolodny and Wallace (2003).

${ }^{22}$ Broome, “Are Intentions Reasons?” p. 99-emphasis added. Broome also writes that “...it is not credible that, just by adopting some end, you make it the case that you have reason to pursue it" (Broome, "Have We Reason to Do as Rationality Requires? A Comment on Raz,” p. 1).
} 
But even this version of the bootstrapping objection flies in the face of the abovecited fact that psychological relations to the world do give us defeasible reasons to do all sorts of things. So, the wizardry argument is just another clunky bit of philosophical sleight of hand: it looks like an argument but it really is just an instance of someone baldly begging the question. For, it is far more evident that mental states alone-even suboptimal mental states-can change the balance of reasons than it is that intentions formed on the basis of acceptable deliberations cannot shift the balance of reasons.

For example, that A (non-pathologically) loves B is a reason for A to treat B differently than A would treat someone she does not love, even if $\mathrm{B}$ is not the perfect candidate for A's love. ${ }^{23}$ If A stops loving B then A loses her reason to treat $\mathrm{B}$ in the special loving manner. The explanation for all this is that there is a principle that says that loving someone is valuable, and there is a fact about the nature of that value, namely that properly responding to it requires treating the beloved differently than those one does not love. This principle and this fact about what it is to properly love someone together make the fact that A loves B a defeasible reason in favor of A treating B differently than someone she does not love, even if that someone A does not love is in some ideal sense a better candidate for A's love. ${ }^{24}$ Thus, a psychological attitude_-loving someone_creates a reason 'out of nothing.'

In general, (non-pathologically) valuing something gives both the valuing agent and others who do not share those values reasons to act in certain ways, namely, ways that involve treating those things differently than things that are not valued. For example, if I value counting blades of grass, then I have a pro tanto reason to count blades of grass and others have pro tanto reasons to allow me to count blades of grass. The same applies, mutatis mutandis, to valuing playing video games, valuing jogging for its own sake, and so on. ${ }^{25}$ On this view, A's caring about $\mathrm{O}$ or A's valuing $\mathrm{O}$ is a pro tanto reason for $\mathrm{A}$ to cherish, engage with, and promote $\mathrm{O}$, regardless of whether $\mathrm{O}$ is the best available candidate for A's valuing. ${ }^{26}$ By coming to value something, someone creates a reason for herself and for others 'out of nothing.'

The wizardry argument offers no independent grounds to think that intentions are any different from promises, loves, or values. All that can be said for the wizardry argument is that it points out that we do not yet have an argument one way or

\footnotetext{
${ }^{23}$ For more exploring (and challenging) this point, see e.g., Velleman (1999), Kolodny (2003); and the papers collected in Solomon and Higgins (1991).

24 I do not want to take sides in the buck-passing debate. Everything I say here can be around from a value-first to a reasons-first view without affecting the argument.

25 See Darwall (2001), Jaworska (2007), and Smith (2013).

26 There are plenty of activities that are in themselves totally pointless beyond our valuing them or our caring about them. It is in virtue of our caring about or valuing these activities that we thereby come to have reasons to perform them and others come to have reasons to accommodate us in doing so. These reasons may not be conclusive, but they are there. The idea is that in response to the question, "Why should I treat that person or thing specially?" a perfectly good answer is, "Because you love her" or "Because you care about it." The reason one correctly cites in response to the question, "Why should I do this?" is a psychological state and not something about what that psychological state refers to (although that would be okay as well). I am influenced here by Hieronymi (2005).
} 
another about whether intentions are like loves, cares, or values. All the wizardry argument does is express an undefended prejudice against bootstrapping.

The argument about whether bootstrapping is possible is therefore joined around the question of whether intentions are sufficiently unlike loving, caring, and valuing such that being in the intending-to- $\varphi$ relation cannot matter in the ways that being in the loving-, caring-, and valuing-relations matter. ${ }^{27}$

\section{Conclusion}

Whatever rational force the bootstrapping objection has, it probably has it only when applied to evil and akratic intentions. For, we lack a widely known version of the bootstrapping objection that demonstrates that all non-akratic and non-evil intentions to $\varphi$ are not reasons to $\varphi$. So, for now, we should suspend judgment about whether (more or less) deliberatively sound intentions are reasons. This would allow us to profitably turn our philosophical attentions to the following two questions, in reverse order of their introduction in this essay:

1. How do intentions compare with loving and valuing attitudes when it comes to their reason-giving or reason-triggering capacities?

2. At what point do deliberations become so bad that we have very strong reason to abandon the products of those deliberations and reconsider the question at hand?

Non-dogmatically engaging question 1 would help us to resolve the issue of bootstrapping. I hypothesize that we would find many similarities between values and intentions that would speak in favor of bootstrapping. Engaging Question 2 involves working the functions and normative significance of different forms of practical deliberation. This, I believe, becomes especially salient if we have any sort of answer to Question 1 that finds similarities across the attitudes of intending, caring, valuing, and loving. For, my hypothesis is that since deliberations are expressions of our most cherished rational capacities (namely our capacities to shape our own lives through the use of rational reflection and projection), we will conclude that we ought to be somewhat generous in the errors we allow for in our deliberations. Regardless of the ultimate worth of this very tentative hypothesis, the questions inspiring their formation are significant. But, such questions can only be fully appreciated once we abandon the anti-bootstrapping dogma.

Acknowledgments I thank Luca Ferrero, Ted Parent, Nishi Shah, Justin Weinberg, and Eric Wiland for generously reading drafts of this essay and then providing valuable comments. This paper also benefited from extensive conversations with Michael Bratman and Stephen Darwall. Kieran Setiya provided invaluable guidance regarding a few key ideas. Justin Weinberg suggested the title.

\footnotetext{
${ }^{27}$ For accounts of intentions as playing roles much like cares and values, see Bratman, "Intentions, Practical Rationality and Self-Governance." See also a discussion that strongly suggests such a view in Copp (2007).
} 
Open Access This article is distributed under the terms of the Creative Commons Attribution 4.0 International License (http://creativecommons.org/licenses/by/4.0/), which permits unrestricted use, distribution, and reproduction in any medium, provided you give appropriate credit to the original author(s) and the source, provide a link to the Creative Commons license, and indicate if changes were made.

\section{References}

Bratman, M. (1987). Intentions, plans and practical reasons (pp. 24-27). Cambridge, MA: Harvard University Press.

Bratman, M. (2009). Intentions, practical rationality and self-governance. Ethics, 119, 411-443.

Broome, J. (2001). Are intentions reasons? In Christopher Morris \& Arthur Ripstein (Eds.), Practical rationality and preference: Essays for David Gauthier (pp. 98-120). Cambridge: Cambridge University Press.

Broome, J. (2004). Reasons. In R. Jay Wallace, et al. (Eds.), Reason and value (pp. 28-55). Oxford: Oxford University Press.

Broome, J. (2005a). Does rationality give us reasons? Philosophical Issues, 15, 321-337.

Broome, J. (2005b). Have we reason to do as rationality requires? A comment on Raz. Journal of Ethics and Social Philosophy, 1, 1-8.

Cohen, S. (2002). Basic knowledge and the problem of easy knowledge. Philosophy and Phenomenological Research, 65, 309-329.

Cohen, S. (2010). Bootstrapping, defeasible reasoning, and a priori justification. Philosophical Perspectives, 24, 141-159.

Copp, D. (Ed.) (2007) The normativity of self-grounded reason. In Morality in a natural world (pp. 309-353). Cambridge: Cambridge University Press.

Cullity, G. (2008). Decisions, reasons and rationality. Ethics, 119, 57-95.

Darwall, S. (2001). Because i want it. Social Philosophy and Policy, 18, 129-153.

Enoch, D. (2011). Giving practical reasons. Philosophers, 11(4), 1-22.

Ferrero, L. (2010). Decisions, diachronic autonomy \& the Division of deliberative labor. Philosophers, $10(2), 1-23$.

Gibbard, A. (1990). Morality as consistency in living. Ethics, 110, 140-164.

Hieronymi, P. (2005). The wrong kind of reason. Journal of Philosophy, 102(9), 437-457.

Hinchman, E. (2003). Trust and diachronic agency. Noûs, 37, 25-51.

Holton, R. (1999). Intention and weakness of will. Journal of Philosophy, 96, 241-262.

Holton, R. (2004). Rational resolve. Philosophical Review, 113, 507-535.

Hume, D. (1742/1978). In L. A. Selby-Bigge \& P. H. Nidditch (Eds.) A treatise of human nature, 2 nd ed. (pp. 520-521). Oxford: Oxford University Press.

Jaworska, A. (2007). Caring and full moral standing. Ethics, 117, 460-497.

Kolodny, N. (2003). Love as valuing a relationship. Philosophical Review, 112, 135-189.

Kolodny, N., \& Wallace, R. J. (2003). Promises and practices revisited. Philosophy \& Public Affairs, 31, $119-154$.

Korsgaard, C. (1997). The normativity of instrumental reason. In G. Cullity \& B. Gaut (Eds.), Ethics and practical reason (pp. 215-254). Oxford: Oxford University Press.

Pillar, C. (2013). The bootstrapping objection. Organon F, 20(4), 612-631.

Raz, J. (2005). Instrumental rationality: A reprise. Journal of Ethics and Social Philosophy, 19, 1-19.

Scanlon, T. (1990). Promises and practices. Philosophy \& Public Affairs, 19, 199-226.

Scanlon, T. (1998). What we owe to each other. Cambridge, MA: Harvard.

Schroeder, M. (2005a). Instrumental mythology. Journal of Ethics and Social Philosophy, 1, 1-12.

Schroeder, M. (2005). Cudworth and normative explanations. Journal of Ethics and Social Philosophy $1(3), 1-27$.

Setiya, K. (2007). Cognitivism about instrumental reason. Ethics, 117, 647-673.

Setiya, K. (2014). Intentions, plans, and ethical rationalism. In M. Vargas \& G. Yaffe (Eds.), Rational and social agency: The philosophy of Michael Bratman (pp. 56-82). Oxford: Oxford University Press.

Smith, M. N. (2013). The importance of what they care about. Philosophical Studies, 165, 297-314. 
Solomon, R. C., \& Higgins, K. M. (1991). The philosophy of (Erotic) love. Lawrence, Kan: University of Kansas Press).

Street, S. (2009). In defense of future tuesday indifference: Ideally coherent eccentrics and the contingency of what matters. Philosophical Issues, 19, 273-298.

Velleman, J. D. (1999). Love as a moral emotion. Ethics, 109, 338-374.

Vogel, J. (2008). Epistemic bootstrapping. Journal of Philosophy, 105(9), 518-539.

Weisberg, J. (2012). The bootstrapping problem. Philosophy Compass, 7, 597-610. 